\title{
KNOWLEDGE AND PRACTICE AMONG THE CARETAKERS OF BEDRIDDEN PATIENTS ON PREVENTION OF URINARY TRACT INFECTION
}

\author{
Khanal $\mathbf{N}^{1}$
}

\section{ABSTRACT}

INTRODUCTION: Urinary tract infection (UTI) is one of the major complications of immobility or bedridden condition. Between 46-59\% of spinal cord injury patients develop urinary tract infection during the first year of trauma. UTI is a second most common type of infection, accounting for nearly $25 \%$ of all infections and a serious health problem affecting millions of people each year. The findings of the study might be helpful to the long term care health institution for the development the strategies to involve the caretakers to prevent urinary tract infection in bedridden patients.

OBJECTIVE: The purpose of the study was to find out the level of knowledge and current practice of caretakers of bedridden patients on prevention of urinary tract infection.

METHODS: The descriptive and cross-sectional study design was adopted in this study. A self-prepared structured interview questionnaire and observation checklist was used to collect data from 30 caretakers of hospitalized bedridden patients of Nepal Orthopedic Hospital and Spinal Injury Rehabilitation Center Jorpati implying purposive \& convenient sampling technique.

RESULTS: Out of 30 caretakers, no one had adequate ( $>80 \%)$ knowledge and $46.6 \%$ had moderate $(50-80 \%)$ knowledge and $53.3 \%$ had low $(<50 \%)$ knowledge on meaning, high risk group, contributing factors, signs \& symptoms, consequences and preventive measures of UTI as a whole. Caretaker's preventive practices of UTI for their bedridden patients were not satisfactory except encourage the patient for drinking 2-3 liters water per day.

CONCLUSION: Majorities (53.3\%) of the caretakers of bedridden patients had low level knowledge on preventive measures of UTI. Similarly UTI preventive practices of caretakers were also not satisfactory. Therefore, awareness raising programme on preventive measures of UTI need to be organized specially for caretakers.

KEYWORDS: Knowledge and Practice ofUTI, Nepal Orthopedic Hospital, Spinal Injury Hospital, Bedridden patient

\author{
For Correspondence \\ Mrs. Narbada Khanal \\ Associate Professor \\ Universal College of Nursing Sciences, \\ Bhairahawa, Nepal \\ Email: narbadakhanal@gmail.com
}




\section{INTRODUCTION}

Patients mobility is restricted due to pain, paralysis, loss of muscles strength, systemic disease and use of immobilizing devise like cast, brace, traction etc. Frequently, patients are placed on bed rest or limited their activities for therapeutic purpose. Spinal fracture, lower limbs fracture, pelvic fracture and multiple limbs fracture require prolong immobilization to maintain skeletal alignment to enhance bone healing. Immobility \& bed rest (bedridden condition) brings many physiological complications if appropriate care is not provided.

Urinary tract infection (UTI) is one of the major complications of immobility or bedridden condition that influences the health and quality of life with enormous cost to the health system. Between 46-59\% of spinal cord injury patients develop urinary tract infection during the first year of trauma ${ }^{1}$. Likewise, untreated or persistent UTI may cause other more serious complications such as kidney damage and prostate infections ${ }^{2}$. Renal failure is one of the major causes of recurrent UTI that increase the mortality rate of bedridden patient. Although, effective treatment may resolve lower urinary tract infection (cystitis) by decreasing the duration of symptoms and incidence of progression to upper urinary tract infection.

The Escherichia coli (E.coli), gram-negative bacteria are responsible for $80 \%$ to $85 \%$ of cystitis and stool is a common and major source of UTI. Therefore, bowel incontinent patients developed UTI almost three times more than bowel continent patients. ${ }^{3}$ Likewise, use of indwelling urinary catheters and duration is the most significant risk factors to develop urinary tract infections. The risk of UTI rises from $19 \%$ for 5 days long catheterization to $50 \%$ for 14 days. ${ }^{4}$ European national prevalence studies show that urinary tract infections account for $23.49 \%$ of all nosocomial infections. Among the nosocomial urinary tract infections, $62.8 \%$ are catheter associated. Catheter associated UTI can be prevented by maintaining closed drainage system and using silvercoated catheter. The costs for the prevention, detection and treatment of UTI significantly affect a country's health-care budget so that, decreasing in the UTI rate would have important economic implications.

UTI is a preventable disease. It can be prevented if appropriate preventive measures are adopted while providing care to the patient. Appropriate patient education is necessary to help the client understand the process and follow an effective treatment plan to prevent urinary tract infection. ${ }^{2}$ Nurses are the main professional components of the front line staff in most health system. Nursing care is essential to catch their developmental goals for safe and effective care. But the world has entered into a critical period of shortage of nurses. The scarcity of nurses is being highlighted as one of the obstacles to achieve the wellbeing of the global population. ${ }^{6}$ Therefore, the caretakers are the key persons to prevent complications of bedridden condition. Caretakers should be included while caring bedridden patients for continuity of the care during and after hospitalization. If the caretakers have adequate knowledge and skills, they can incorporate that knowledge and skills while providing care to the patient continuously. Therefore, the main purpose of the study was to find out the level of knowledge and practices of caretakers 'of bedridden patient to prevent urinary tract infection.

\section{METHOD AND MATERIALS}

Descriptive and cross-sectional study design was adopted in this study. The study was carried out in Nepal Orthopedic Hospital (NOH) and Spinal Injury \& Rehabilitation Centre, Jorpati, (SIARC). The population of the study consisted of all caretakers who were attending of their bedridden patients continuously at least for 7 days. A total 30 caretakers; 9 from Nepal Orthopedic Hospital and 21 from Spinal Injury Rehabilitation Center Jorpati were selected purposively and available during the time of data collection.

Structured interview questionnaire (translated in Nepali language) was developed to collect the information about meaning, risk group, contributing factors, signs \& symptoms, consequences and preventive measures of UTI. An observation check list was developed to measure the activities carried out by the caretakers to prevent UTI. Observation checklist-A, that consisted "encourage the patient for drinking 2-3 liters water per day", "avoid to drink bladder irritating fluids", "use clean and dry urinal / bedpan" and "wipe the perineal area from front to back after defecation" for all caretakers and encourage to void 2-3 times per day for those caretakers whose patients were not with Foley's catheter. An observation checklist-B, that consisted "hang the urinary bag below the bladder level of the patient", "change the catheter once a week", "get the urinary bag replace every three days", "do the perineal care once a day" and do Kegal exercise" for those caretakers whose patients were with Foleys catheter. Validity of the tools was maintained by searching the available literature and consultation with urologist, neurologist and orthopedic surgeon. Reliability of the instrument was maintained by pre-testing the interview questionnaire with the 5 caretakers of orthopedic ward in Nepal Medical College.

Before collecting data, permission was obtained from the $\mathrm{NOH}$ and SIARC, Jorpati. The researcher herself was collected the data from mid of August to mid of September 2006 within 4 weeks period. Informed verbal consent has 
taken from all the caretakers who participated in the study. Knowledge was measured by administering structured interview questionnaire among 30 caretakers of bedridden patients. Practices were observed by using observations check list-A and $B$ on those caretakers who were participated in interview. The researcher instructed the caretakers to show the amount of water drinking by the patient to the researcher from $8 \mathrm{am}$ to $4 \mathrm{pm}$ and to the nursing staff from $4 \mathrm{pm}$ to $8 \mathrm{am}$ (when the researcher was not available) for recording in intake and output chart (Nursing Note) each time within 24 hours. The next day, researcher herself calculated the total amount of water taken by the patient within 24 hours on previous day. Likewise, the researcher herself observed each caretaker practices related to use of urinal/bedpan and wiping from front to back at the same time after long toileting of the patient. Furthermore, caretaker's practices related to hang urinary bag below the bladder level of the patient, do perineal care and encourage the patient to perform Kegel's exercise were observed and recoded the date of urinary catheter change and urinary bag change on nursing note. All interview forms and checklists were reviewed for completeness by the researcher herself and was checked the correctness and accuracy before leaving from the field work.

The questionnaire was re-checked for the completeness and correctness. Identification number was given orderly as code number for each interviewed questionnaire and observation checklist before entering the data. SPSS version 16 computer software programme was used for entering, cleaning and analysis of the data about preventive measures of urinary tract infection. Analyzed data were reported in descriptive statistics such as frequency, percentage, mean and standard deviation. To calculate the mean knowledge in each multiple responses answer about different aspects of urinary tract infection, the number of correct answer/answers was considered as frequency ( $f$ ) whereas the number of item in this concept was considered as observation (x), response of all subjects was counted separately. Similarly, in negative response option 'NO' was considered as correct answer.

\section{RESULT}

Out of 30 caretakers, majority (60\%) were female and $40 \%$ male. The maximum (30\%) of the caretakers were Brahman, followed by Chhetri, Tamang, Newar, Rai and others (Pariyar) by $26.6 \%, 20 \%, 16.6 \%, 3.3 \%$, and $3.3 \%$ respectively and 76.7\% were literate. Regarding caretaker's relation with patient, $86.6 \%$ were family members and only $13.3 \%$ were paid caretakers (non professional). Among the family members, $36.6 \%$ were housewives. The mean age of the caretakers was 34 years.
Table 1: Caretakers' Knowledge on UTI: Meaning

\begin{tabular}{|l|c|c|c|c|}
\hline Items & Number & Percent & Mean & $\begin{array}{l}\text { Standard } \\
\text { Deviation }\end{array}$ \\
\cline { 1 - 3 } $\begin{array}{l}\text { Multiplication of micro- } \\
\text { organism with in the } \\
\text { urinary passage }\end{array}$ & 14 & 46.6 & 0.76 & 0.93 \\
\hline $\begin{array}{l}\text { *Formation of stone with } \\
\text { in the urinary passage }\end{array}$ & 4 & 13.3 & & \\
\cline { 1 - 3 } *Renal failure & 5 & 16.6 & & \\
\hline
\end{tabular}

* Negative responses ('No' is Correct answer) Multiple Responses

Only $46.6 \%$ of the caretakers could define the term urinary tract infection correctly. The mean score on meaning of urinary tract infection was found 0.76 with the standard deviations of 0.93 .

Table 2: Caretakers' Knowledge on UTI: High Risk Group

\begin{tabular}{|l|c|c|c|c|}
\hline High Risk Group & Number & Percent & Mean & $\begin{array}{c}\text { Standard } \\
\text { Deviation }\end{array}$ \\
\hline Adult Female & 12 & 40.0 & & \\
*Adult Male & 5 & 16.6 & 1.50 & 1.71 \\
Elderly Female & 9 & 30.0 & & \\
Elderly Male & 12 & 40.0 & & \\
* Under 5 Male Children & 3 & 10.0 & & \\
Under 5 Female Children & 4 & 13.3 & & \\
\hline
\end{tabular}

* Negative Responses ('No' is Correct Answer) Multiple Responses

The maximum $(40 \%)$ of the caretakers reported that adult female \& elderly male and only $13.3 \%$ of the caretakers said under 5 female children are the high-risk group for UTI and the mean score was found 1.50 with the 1.71 standard deviation.

Table 3: Caretakers' Knowledge on UTI: Contributing Factors

\begin{tabular}{|l|l|l|l|l|}
\hline Contributing Factors & Number & Percent & Mean & $\begin{array}{l}\text { Standard } \\
\text { Deviation }\end{array}$ \\
\hline Inadequate fluid intake & 22 & 73.3 & 3.50 & 2.25 \\
\cline { 1 - 3 } Stagnation of urine & 20 & 66.6 & & \\
\hline leakage of urine & 12 & 40.0 & & \\
\hline Insertion of catheter & 14 & 46.6 & & \\
\hline Poor perineal hygiene & 19 & 63.3 & & \\
\hline *Loss of appetite & 7 & 23.3 & & \\
\hline Multiple sex partner & 11 & 36.6 & & \\
\hline
\end{tabular}

* Negative Response ('No is Correct Answer) Multiple Responses 
The majorities $(73.3 \%)$ of the caretakers knew inadequate fluid intake, $66 \%$ knew stagnation of urine, $63.3 \%$ knew poor perineal hygiene and $40.0 \%$ of the caretakers knew leakage of urine \& $36.6 \%$ knew multiple sex partner are contributing factors of UTI. The mean score on knowledge about contributing factors of UTI was found 3.50 with the standard deviations of 2.25 .

Table 4: Caretakers' Knowledge on UTI: Signs/ Symptoms

\begin{tabular}{|l|l|l|l|l|}
\hline Signs/Symptoms & Number & Percent & Mean & $\begin{array}{l}\text { Standard } \\
\text { Deviation }\end{array}$ \\
\hline Burning urination & 22 & 73.3 & & \\
\hline Milky\& cloudy urine & 16 & 53.3 & 4.90 & 3.33 \\
\hline Frequent urination with less urinary output & 12 & 40 & & \\
\hline Red \& swollen urinary passage & 17 & 56.6 & & \\
\hline Fever with shriving & 13 & 43.3 & & \\
\hline Urgency of urination & 14 & 46.6 & & \\
\hline Blood in urine & 15 & 50.0 & & \\
\hline Lower abdomen pain & 16 & 53.3 & & \\
\hline *Heart burn & 7 & 23.3 & & \\
\hline Loin pain & 7 & 23.3 & & \\
\hline Nausea \& vomiting & 8 & 26.6 & & \\
\hline
\end{tabular}

\section{* Negative Response ('No' is Correct Answer) Multiple} Responses

Table 4 reveals that the majorities (73.3\%) of the caretakers knew burning urination, $56.6 \%$ knew red swollen urinary passage and $43.3 \%$ knew increased urination with less urinary output are the signs \& symptoms of UTI. Similarly, $53.3 \%$ of the caretakers' verbalized lower abdomen pain and milky/cloudy urine, $46.6 \%$ urgency of urination, $43.3 \%$ fever with shriving, $26.6 \%$ nausea/vomiting and $23.3 \%$ loin pain are also the signs and symptoms of urinary tract infection. The mean score on knowledge about signs and symptoms of UTI were found 4.90 with the standard deviations of 3.27 .

Table 5: Caretakers' Knowledge on UTI: Consequences

\begin{tabular}{|l|c|c|c|c|}
\hline \multicolumn{1}{|c|}{ Consequences } & Number & Percent & Mean & $\begin{array}{c}\text { Standard } \\
\text { Deviation }\end{array}$ \\
\cline { 1 - 3 } Individual \& family stress & 22 & 73.3 & 2.56 & 1.73 \\
\cline { 1 - 3 } Prolong hospitalization & 21 & 70.0 & & \\
\cline { 1 - 3 } Renal failure & 16 & 53.3 & & \\
\cline { 1 - 3 } Anemia & 6 & 20.0 & & \\
\cline { 1 - 3 } Financial overload & 12 & 40 & & \\
\hline
\end{tabular}

Multiple Responses

Regarding consequence of UTI, the majorities (73.3\%) of the caretakers said individual and family stress, $70 \%$ said prolong hospitalization, $53.3 \%$ said renal failure, $40 \%$ said financial overload and only $20 \%$ of the caretakers said anemia as the consequences of UTI. The mean score on knowledge about consequences of UTI was found 2.56 with the standard deviations of 1.73 .

Table 6: Caretakers' Knowledge on UTI: Preventive Measures

\begin{tabular}{|c|c|c|c|c|}
\hline Preventive Measures & Number & Percent & Mean & $\begin{array}{l}\text { Standard } \\
\text { Deviation }\end{array}$ \\
\hline Drink plenty of fluid & 24 & 80 & \multirow{21}{*}{7.43} & \multirow{21}{*}{4.62} \\
\hline Allow to drink fruit juice & 18 & 60 & & \\
\hline Allow to drink water & 23 & 76.6 & & \\
\hline Drink 2-3 liter of water per day & 4 & 13.3 & & \\
\hline \multicolumn{3}{|l|}{ Avoid bladder irritating fluid intake } & & \\
\hline - alcohol & 21 & 70 & & \\
\hline - $\quad$ coffee & 7 & 23.3 & & \\
\hline - citrus juice & 7 & 23.3 & & \\
\hline $\begin{array}{l}\text { Wiping from front to back after } \\
\text { defecation }\end{array}$ & 11 & 36.6 & & \\
\hline Using clean \& dry urinal/bedpan & 20 & 66.6 & & \\
\hline $\begin{array}{l}\text { Hanging urinary bag below the level of } \\
\text { urinary bladder of the patient }\end{array}$ & 19 & 63.3 & & \\
\hline Changing urinary bag every three days & 0 & 0.0 & & \\
\hline Changing urinary catheter once a week & 2 & 6.6 & & \\
\hline Doing catheter care once a day & 11 & 36.6 & & \\
\hline Voiding at least $2-3$ hours interval & 17 & 56.6 & & \\
\hline $\begin{array}{l}\text { Changing the position of the patient } \\
\text { every 2-3 hours interval }\end{array}$ & 13 & 43.3 & & \\
\hline $\begin{array}{l}\text { Connecting the urinary catheter with } \\
\text { urinary bag safely. }\end{array}$ & 20 & 66.6 & & \\
\hline Know the meaning of kegel's exercise & 4 & 13.3 & & \\
\hline Doing kegel's exercise & 2 & 6.6 & & \\
\hline Doing kegel's exercise 26 times per day & 0 & 0.0 & & \\
\hline Do kegal exercise 8-10 times per day & 0 & 0.0 & & \\
\hline
\end{tabular}

\section{Multiple Responses}

Regarding preventive measures of UTI, $80 \%$ caretakers reported that plenty of fluids need to drink but only $13.3 \%$ reported 2-3 liters of water drinking per day as the measures to prevent UTI. Likewise, $66.6 \%$ of caretakers knew using clean \& dry urinal/bedpan, $63.3 \%$ knew hanging urinary bag below the level of urinary bladder of the patient and $56.6 \%$ knew voiding at least 2-3 hours interval are the measures to prevent UTI. None of the 30 caretakers knew that changing the urine collecting bag every three days and doing Kegel's exercise (exact frequency) as a preventive measure of UTI. The mean score on knowledge about preventive measures of UTI was found 7.43 with standard deviations of 4.62 . 
Table 7: Level of Knowledge on UTI as a whole

\begin{tabular}{|l|l|l|l|l|l|}
\hline Level of Knowledge & Frequency & Percentage & Total score & Mean & $\begin{array}{l}\text { Standard } \\
\text { Deviation }\end{array}$ \\
\hline High $(>80 \%)$ & 0 & $0.0 \%$ & \multirow{2}{*}{52} & \multirow{2}{*}{20.66} & 12.67 \\
\cline { 1 - 3 } Moderate $(50-80 \%)$ & 14 & $46.6 \%$ & & & \\
\cline { 1 - 3 } Low $(<50 \%)$ & 16 & $53.3 \%$ & & & \\
\hline
\end{tabular}

The total knowledge score on urinary tract infection as a whole (meaning, risk factors, contributing factors, signs \& symptoms, consequences and preventive measures) were 52 . Based on score obtained by the caretakers on knowledge about UTI was categorized in three levels; high, moderate and low knowledge. Out of 30 caretakers, no one scored as high $(>80 \%)$ knowledge, $46.6 \%$ of the caretakers scored as average $(50-80 \%)$ and $53.3 \%$ scored as low $(<50 \%)$ knowledge. The mean score on knowledge as a whole was found 20.66 with standard deviations of 12.67 .

\section{Table 8: Caretakers' Practice to Prevent UTI}

\begin{tabular}{|l|c|c|}
\hline $\begin{array}{l}\text { Practices of Respondents to Prevent } \\
\text { Urinary Tract Infection (30) }\end{array}$ & Number & Percent \\
\hline $\begin{array}{l}\text { Encourage the patient for drinking 2-3 liters of } \\
\text { water per day }\end{array}$ & 23 & 76.6 \\
\hline Avoid bladder irritating fluids & 2 & 6.6 \\
\hline $\begin{array}{l}\text { Wipe the perineal area from front to back } \\
\text { after defecation }\end{array}$ & 1 & 3.3 \\
\hline Use clean and dry urinal/ bedpan & 14 & 46.6 \\
\hline Encourage to void 2-3 hours interval (n=19) & 3 & 15.7 \\
\hline $\begin{array}{l}\text { Practice of Respondents' whose Patient } \\
\text { were with Foleys Catheter (n=11) }\end{array}$ & & \\
\hline $\begin{array}{l}\text { Hang the urinary bag below the bladder } \\
\text { level of the patient }\end{array}$ & 1 & 3.3 \\
\hline Change the urinary catheter once a week & 0 & 0.0 \\
\hline Get the urinary bag replaced every thre days & 0 & 0.0 \\
\hline Do perineal care once a day & 0 & 0.0 \\
\hline Encourage to do kegel's exercise & 0 & 0.0 \\
\hline
\end{tabular}

Out of 30 caretakers, majorities (76.6\%) were encouraged their patient for drinking 2-3 liter of water to flush out the micro-organism from urinary passage. Similarly, 3.3\% the caretakers cleaned their patients' perineal area from front to back after defecation, $6.6 \%$ of them avoid to drink bladder irritating fluids like, coffee, alcohol and citreous juice and only $46.6 \%$ used clean and dry urinal/bedpan. Furthermore, 19 caretakers whose patients were not with Foley's catheter, $15.7 \%$ of them encouraged their patients for voiding within 2 3 hours interval. Likewise, 11 caretakers whose patient were with Foley's catheter, only $3.3 \%$ (1) were hung the urine collecting bag below the bladder level of the patient and none of them changed the urinary catheter once a week, urine collecting bag every three days, perineal care once a day and encouraged to do kegel's exercise.

\section{DISCUSSIONAND CONCLUSION}

This study revealed that majority $(60 \%)$ of the caretakers were female, this may be due to the caring role of Nepalese women in the society. Generally, family member found to be the caretaker during sick in the Nepalese society but this study showed that $13.3 \%$ caretakers were hired for long term care. It indicates caring role is changing from family member to paid caretakers in Nepalese society too.

People must know about the definition, risk factors, signs \& symptoms and preventive measures of UTI. If people have adequate knowledge, then only they can use their knowledge to prevent catheter related UTI. This study found that no one of the caretakers had adequate knowledge about definition, risk factors, signs \& symptoms, complications and preventive measures of UTI. Similar findings was found in one study conducted by Wilde ${ }^{7}$ in the community with the people having indwelling catheter and almost all of them were unaware about risk factors, symptoms and preventive measures of UTI.

The Escherichia coli (E.coli), gram-negative bacteria are responsible for $80 \%$ to $85 \%$ of cystitis and stool is a common and major source of UTI. Therefore, bowel incontinent patients developed UTI almost three times more than bowel continent patients. ${ }^{3}$ In this study, it is found that $66.6 \%$ of caretakers knew using clean \& dry urinal/bedpan and $36.6 \%$ wiping from front to back after defecation as the preventive measures of UTI but in practice $46.6 \%$ were using clean \& dry urinal/bedpan and only $3.3 \%$ wiping from front to back after defecation.

The risk of UTI rises from $19 \%$ for 5 days long catheterization to $50 \%$ for 14 days. ${ }^{4}$ In this study it is found that only $2.2 \%$ of caretakers knew that urinary catheter should be changed once a week but no one changed the catheter once a week.

Urinary blockage is one of the contributing factors for UTI. To increase fluid intake is one of the measures to prevent urinary blockage. This study showed that $80 \%$ of caretakers knew that plenty of fluids intake is one of the preventive measures of UTI and $76.6 \%$ caretakers encouraged their patient to drink 2-3 liters of water per day. A study was carried out by Wilde ${ }^{8}$ with 24 patients having an indwelling urinary catheter for at least 3 months. Among them 13 experienced blockage. Those who experienced blockage, 6 developed UTI during the 6 months 
of the review. Therefore, the nurses or caretakers encouraged or taught their patients to increase fluid intake to prevent urinary blockage.

\section{CONCLUSION}

UTI is a second most common infection among the nosocomial infections and brings many undesirable complications including death. Infection can be prevented if appropriate preventive measures are adopted by the high risk patient and care takers or providers. This study was conducted to find out the level of knowledge and practices of caretakers on UTI and its preventive measures among bedridden patient.

Out of 30 caretakers, no one $(0 \%)$ had adequate knowledge and $46.6 \%$ had average level knowledge and $53.3 \%$ had low level of knowledge on preventive measures of UTI. Mean score of overall knowledge score was 52 and based on obtained score by the caretakers, mean score was calculated and found 20.66 with standard deviation 12.67 on different aspect of preventive measures of UTI. It indicates that the majorities of the caretakers had less knowledge about the meaning, high-risk group, contributing factors, signs \& symptoms, consequences and preventive measures of UTI.

Similarly, this study revealed that practices of caretakers, $76.6 \%$ were encouraged to drink $2-3$ liter of water and $46.6 \%$ used clean and dry urinal/bedpan but other practices like, avoid drinking bladder irritating fluids like, coffee, alcohol and citreous juice, cleaning patients' perineal area from front to back after defecation and other catheter related activities were not satisfactory. From this finding it can be concluded that knowledge and practice increasing programme should be organized specially for caretakers on preventive measures of UTI.

\section{REFERENCES}

1. Tripathi RB, Herm FB, Altrichter. Urinary tract infection and pressure sores at Green Pastures Spinal Injury Unit. JNMA 2003; Vol. 42: 140-142.

2. Towers PM. Urinary tract infection. J Am A cad Nurse Pract 2000; 12(4): 149-54; quiz 155-7.

http://dx.doi.org/10.1111/j.1745-7599.2000.tb00297.x PMid:11930421

3. Lara LL, Troop PR, and Beadleson-BairdM. The risk of urinary tract infection in bowel incontinent men. $J$ Gerontol Nurs1990;16(5): 24-6. PMid:2358644

4. Tasseau F, Chupin A, Pradier C, Villers D, Baron Dand Nicolas F. Study of incidence and risk factors of nosocomial urinary tract infection in patients with indwelling urinary catheter in intensive care units 1990; Agressologie 31: 503-4

5. Gastmeier P. Nosocomial urinary tract infection; many unresolved questions. Clinical microbiology and infection 2001; $7(10): 521-2$.

http://dx.doi.org/10.1046/j.1198-743x.2001.00353.x http://dx.doi.org/10.1046/j.1469-0691.2001.00353.x PMid:11683791

6. Buchan $J$ and Calman L. The global shortage of registered nurses. ICN classification of urinary tract infection 2004. Avalable at www.mercydesmoines.org/adam/wellconnected larticles/000036.asp. Retrieved on 12thJanuary 2007.

7. Wilde MH. Urinary tract infection in people with long-term urinary infection. J Wound Ostomy Continence Nurs 2003; Vol. $30(6): 314-23$.

http://dx.doi.org/10.1016/S1071-5754(03)00437-6 http://dx.doi.org/10.1097/00152192-200311000-00007 PMid:14615760

8. Wilde MH and Carrigan MJ (2003). A chart audit of actors related to urine flow and urinary tract infection. $J$ Adv Nurs2003; Vol. 43(3): 254-62 http://dx.doi.org/10.1046/j.1365-2648.2003.02708.x 